\title{
Dissemination and proliferation of Salmonella typhimurium in genetically resistant and susceptible mice
}

\author{
H. R. XU and H. S. HSU* \\ Department of Microbiology and Immunology, Medical College of Virginia, Virginia Commonwealth University, \\ Richmond, VA 23298, USA
}

\begin{abstract}
Summary. Genetically resistant $\mathrm{A} / \mathrm{J}$ and CBA mice were inoculated intraperitoneally with either $10^{3}$ or $10^{4}$ organisms of a virulent strain of Salmonella typhimurium; susceptible $\mathrm{C} 57 \mathrm{BL} / 6 \mathrm{~J}$ and BALB/c mice were inoculated with either $10^{2}$ or $10^{3}$ organisms. Except with the smaller dose in resistant mice, fatal infection ensued. Bacteraemia occurred within $1 \mathrm{~h}$ after inoculation, except that it was not detectable during the first $6 \mathrm{~h}$ in the susceptible mice inoculated with $10^{2}$ organisms. From day 2 , the circulating bacterial population continued to increase in all infected mice, except that it remained under control in the resistant mice inoculated with the lower dose $\left(10^{3}\right.$ organisms). The pathogen proliferated logarithmically in the liver from day 2, and a bacterial count of $c .10^{8} \mathrm{cfu} / \mathrm{g}$ of tissue was reached when the animals died at 5-7 days; again, the resistant mice inoculated with $10^{3}$ organisms were an exception in which the hepatic bacterial population was kept under control and the mice survived.
\end{abstract}

\section{Introduction}

Host resistance in murine salmonellosis is under genetic control. Inbred mouse strains have been derived with varying degrees of native resistance to the disease, some highly susceptible, others highly resistant. ${ }^{1}$ The variation can in part be demonstrated by the difference in the net bacterial growth in the liver and spleen during the infection. It has been suggested that the difference was attributable to the relative capacity of the host's macrophages to control the rate of bacterial proliferation. ${ }^{2,3}$ Histopathological evidence throws doubt on this contention, because the early lesions in the liver and spleen contain predominantly inflammatory polymorphs rather than macrophages, and also the pathogen replicates extracellularly in lesions and sinusoids as well as within hepatocytes. ${ }^{4}$

The present study was designed to detect dissemination of the pathogen at early stages of the infection and its subsequent proliferation in the liver, in an attempt to ascertain the ability or inability of the host to contain the bacteria. We believe this to be the first step in a systematic analysis of the basic difference between resistant and susceptible hosts.

\section{Materials and methods}

\section{Strain of Salmonella typhimurium}

The virulent strain SR-11 $1^{5}$ was maintained on Tryptic Soy Agar (TSA; Difco) and propagated in Tryptic Soy Broth (TSB; Difco) for $6 \mathrm{~h}$ at $37^{\circ} \mathrm{C}$ in a rotating drum. The organisms were washed in saline and the suspension was standardised optically by the previously described procedure ${ }^{5}$ to contain $c .2 \times 10^{9}$ viable bacteria $/ \mathrm{ml}$.

\section{Mice}

Inbred, male mice weighing $c .20-25 \mathrm{~g}$ were used. A/J mice (Jackson Laboratories, Bar Harbour, ME) and CBA mice (National Cancer Institute, Frederick,

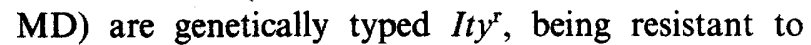
infection with $S$. typhimurium by the intraperitoneal (i.p.) route, with an LD50 of $c .10^{4}$ bacteria. C57BL/6J mice (Jackson Laboratories) and BALB/c mice (National Cancer Institute) are typed Ity $y^{\mathrm{s}}$, being hypersusceptible to a similar infection, with an LD50 of $<10^{2}$ organisms. The animals were housed in the Central Animal Care Facility at the Medical College of Virginia for at least 1 week before they were used.

\section{Infection of mice and sampling of bacteria in blood and liver}

Mice were inoculated i.p. with a designated number of bacteria. Heparinised Natelson capillary tubes 
(Baxter Corp., McGaw Park, IL) were used to obtain 12.5- $\mu$ l samples of blood from the retro-orbital plexus of individual infected mice selected by rotation at designated intervals. Each blood sample was placed in $1 \mathrm{ml}$ of saline and sonicated for $15 \mathrm{~s}$ in a Biosonik II apparatus (Bronwill Scientific, Rochester, NY), at a "needle" probe intensity setting of 30 , to disrupt the leucocytes and to disperse the bacteria. The sample was diluted in saline and plated on TSA to enumerate the bacteria.

Randomly selected mice were killed with ether at daily intervals from day 2 after inoculation. The liver was removed, and weighed after a small section had been taken for histopathological examination. It was then ground in $12 \mathrm{ml}$ of chilled saline in a $20-\mathrm{ml}$ sterilised stainless steel cup with a Waring tissue blender (model 34BL21) at no. 2 setting for 2-3 min. The homogenised tissue was centrifuged at $60 \mathrm{~g}$ for $10 \mathrm{~min}$ at $5^{\circ} \mathrm{C}$ to sediment debris. The absence of intact tissue cells in the supernate was confirmed by microscopy. A sample of it, containing disrupted cells and released bacteria, was diluted for bacterial quantitation on TSA plates.

\section{Results}

\section{Bacterial dissemination and proliferation in resistant $(A / J)$ and susceptible $(C 57 B L / 6 J)$ mice}

Three experiments were performed as follows. The resistant mice were divided into two group of $6-8$ animals each, and inoculated i.p. with either $2 \times 10^{3}$ or $5 \times 10^{4}$ bacteria. Likewise, two groups of 5-6 susceptible mice were inoculated with either $1 \times 10^{2}$ or $2 \times 10^{3}$ bacteria. To assay the level of bacteraemia, peripheral blood samples were taken from one infected mouse in each of these four groups, selected by rotation, at 1, 2, 4, 6, 8, 10 and $24 \mathrm{~h}$ after inoculation. At daily intervals from day 2 , one mouse from each group was bled for bacterial count, and killed; its liver also was removed for bacterial count.

A dose of $2 \times 10^{3}$ bacteria did not cause a fatal infection in the $\mathrm{A} / \mathrm{J}$ mice, whereas a dose of $5 \times 10^{4}$ bacteria was invariably lethal. In contrast, both $1 \times 10^{2}$ and $2 \times 10^{3}$ bacteria induced a rapidly fatal infection in the $\mathrm{C} 57 \mathrm{BL} / 6 \mathrm{~J}$ mice. Figs. $1 \mathrm{~A}$ and $\mathrm{B}$ show the changing bacterial population in the blood and liver, respectively, in the two types of mouse. Each point represents the average bacterial count from three mice in these three experiments.

As seen in fig. $1 \mathrm{~A}$, the pathogen was not isolated from the peripheral blood of the C57BL/6J mice inoculated with $1 \times 10^{2}$ bacteria within the first $6 \mathrm{~h}$ of the infection. On the other hand, bacteraemia was detected within $1 \mathrm{~h}$ in both the C57BL/6J and $\mathrm{A} / \mathrm{J}$ mice inoculated with $2 \times 10^{3}$ bacteria and in the $\mathrm{A} / \mathrm{J}$ mice inoculated with $5 \times 10^{4}$ organisms. From day 2 , the bacterial population in the circulation continued to increase until the mice died (from day 5 onwards),

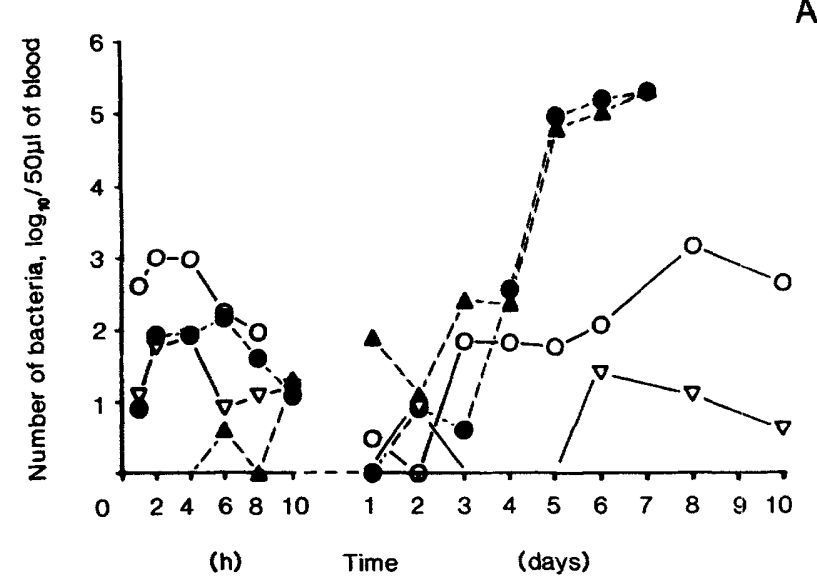

B

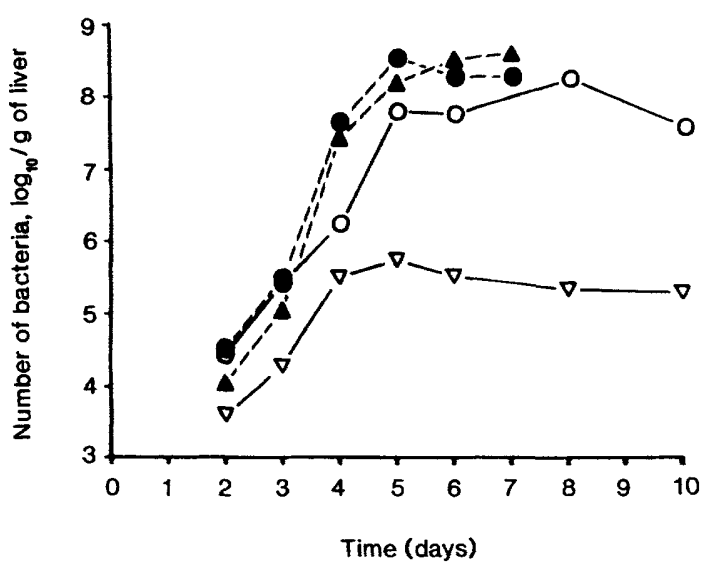

Fig. 1. A, Bacteraemia, and B, bacterial proliferation in the liver, in natively resistant $A / J$ mice and susceptible $C 57 B L / 6 \mathrm{~J}$ mice. The A/J mice were inoculated i.p. with either $2 \times 10^{3}(\nabla)$ or $5 \times 10^{4}(O)$ bacteria, and the $\mathrm{C} 57 \mathrm{BL} / 6 \mathrm{~J}$ mice were inoculated with either $1 \times 10^{2}$ $(\Delta)$ or $2 \times 10^{3}(O)$ bacteria.

except in the $\mathrm{A} / \mathrm{J}$ mice inoculated with $2 \times 10^{3}$ bacteria, which were able to maintain a low level of circulating bacteria and to survive the infection.

Fig. 1 B shows that the number of bacteria increased logarithmically in the liver from day 2 . With the exception of the $\mathrm{A} / \mathrm{J}$ mice inoculated with $2 \times 10^{3}$ bacteria, a bacterial count of $c .10^{8} / \mathrm{g}$ of tissue was reached when mice died-from day 5 among the susceptible C57BL/6J mice and from day 7 among the resistant $\mathrm{A} / \mathrm{J}$ mice. In contrast, the $\mathrm{A} / \mathrm{J}$ mice inoculated with the lower dose of $2 \times 10^{3}$ bacteria were able to contain the bacterial population below $c .10^{6} / \mathrm{g}$ and to retard its subsequent growth.

\section{Bacterial dissemination and proliferation in resistant $(C B A)$ and susceptible $(B A L B / c)$ mice}

The above experiments were repeated with different strains of resistant and susceptible mice. Two groups of $18 \mathrm{BALB} / \mathrm{c}$ mice were inoculated with either $1 \times 10^{2}$ or $2 \times 10^{3}$ bacteria; 21 CBA mice were inoculated with $2 \times 10^{3}$ bacteria and 26 CBA mice with $6 \times 10^{4}$ bacteria. At each designated interval, bacterial counts in the blood and liver were determined from either two or three mice in each of these four groups and the 


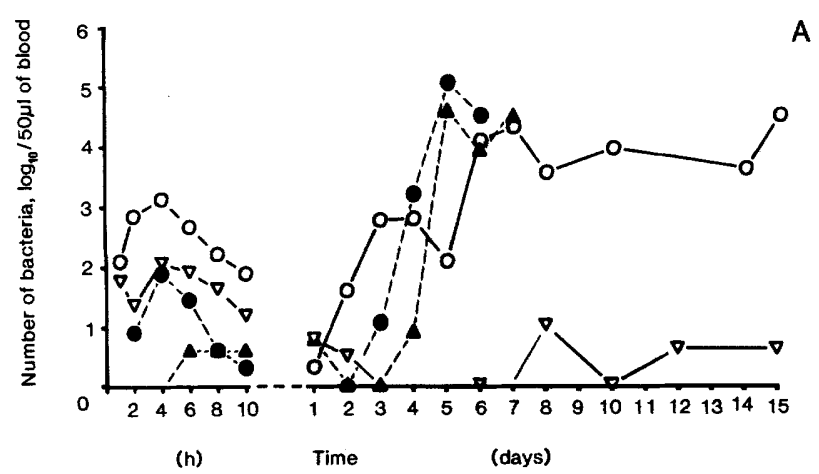

B

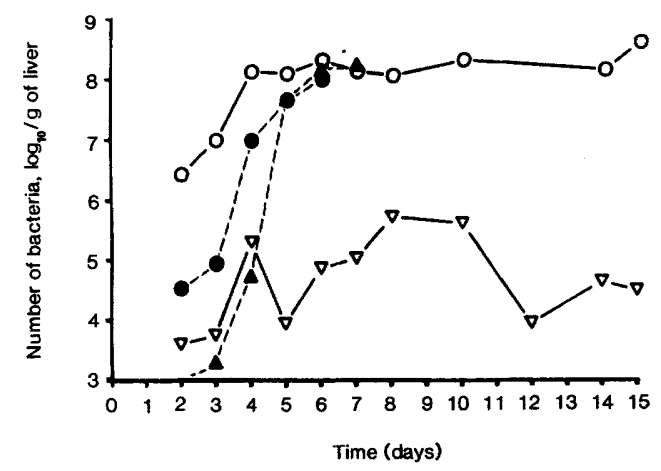

Fig. 2. A, Bacteraemia, and B, bacterial proliferation in the liver, in natively resistant CBA mice and susceptible BALB/c mice. The CBA mice were inoculated i.p. with either $2 \times 10^{3}(\nabla)$ or $6 \times 10^{4}(O)$ bacteria, and the BALB/c mice were inoculated with either $1 \times 10^{2}$ $(\Delta)$ or $2 \times 10^{3}(\mathbf{)})$ bacteria.

averages were plotted in figs. $2 \mathrm{~A}$ and $\mathrm{B}$, respectively.

Consistent with the preceding observations, fig. $2 \mathrm{~A}$ shows that the pathogen entered the circulation within $1 \mathrm{~h}$ after the i.p. inoculation of $2 \times 10^{3}$ and $6 \times 10^{4}$ bacteria, whereas bacteraemia was not detected until $6 \mathrm{~h}$ after inoculation with $1 \times 10^{2}$ bacteria in BALB/c mice. There was also an increase of bacteria in the circulation from day 2 until the animals succumbed to the disease, except in CBA mice inoculated with $2 \times 10^{3}$ organisms. The latter group also controlled the initial bacterial invasion in the liver on day 2 and suppressed the subsequent bacterial growth after day 4 (fig. 2B). Again, only this group survived the disease. In the three other groups, the bacterial count reached $c .10^{8}$ organisms/g of liver; the susceptible BALB/c mice began to die on day 5 and the resistant CBA mice from day 7 .

\section{Discussion}

The Ity gene on chromosome 1 is commonly cited as the primary controlling factor in murine host resistance to salmonellosis. ${ }^{6}$ It appears to affect the net growth rate of virulent $S$. typhimurium in the liver and spleen of inbred mouse strains during infection. ${ }^{1,7-9}$ $\mathrm{A} / \mathrm{J}$ and CBA mice are both genetically typed $I t y^{\mathrm{r}}$ and are consistently resistant to an i.p. inoculation of $10^{3}$ viable units of $S$. typhimurium strain SR-11. In contrast, C57BL/6J and BALB/c mice are genetically typed Ity $y^{\mathrm{s}}$ and invariably succumb to a similar inoculation with $10^{2}$ bacteria. The purpose of the present investigation was to compare the early dissemination and the subsequent proliferation of the pathogen in resistant and susceptible hosts. The organisms were inoculated into the peritoneal cavity to simulate a local primary infection and initiate a systemic infection. The changing bacterial population in the liver was enumerated to represent their proliferation in vivo, because this organ is in the reticuloendothelial system (RES) but not in the lymphoid system.

Treatment of blood by dilution and sonication is likely to disperse the intracellular ${ }^{4}$ as well as extracellular organisms into single bacteria. In contrast, the vigorous grinding of the liver in a Waring blender is unlikely to disintegrate the tissue such that its total viable bacterial population can be released and recovered as individual organisms. But the procedure seems adequate and is suitable for comparative purposes. It is important to reiterate that the increase of bacterial population in an organ, such as the liver or spleen, does not represent the proliferation of the pathogen within host macrophages, nor does its suppression necessarily reflect the expression of antibacterial cellular immunity. ${ }^{4}$

The bacteria disseminated rapidly to establish a systemic infection, as evidenced by the appearance of bacteraemia within $1 \mathrm{~h}$, when $\geqslant 10^{3}$ organisms were inoculated into either the genetically resistant or susceptible mice (figs. $1 \mathrm{~A}$ and $2 \mathrm{~A}$ ). Even when $1 \times 10^{2}$ bacteria were injected into a susceptible host, they became detectable in the blood by $6 \mathrm{~h}$. This affirms the i.p. route as an efficient way of introducing a systemic inoculum. There appeared to be no complete clearance of the bacteria from the circulation during the early infection as one would normally expect. This observation may well be unique to this experimental design, in which the initial growth of the organisms in the peritoneal cavity would continue to dispatch them into the blood. The pathogen undoubtedly gained a foothold in the organs of the RES at an early stage, and its proliferation could be assessed by the net increase in the bacterial population in the liver. In these experiments, the infective doses were low, so that the rapid initial bacterial growth would not be influenced by the effect of endotoxin. Also, consistent with earlier reports, ${ }^{4,10-12}$ the histopathological reactions in these infected livers showed the early accumulation of polymorphs and the absence of macrophages (unpublished observations). Hence, the suggestion that macrophage function may be hindered by endotoxin ${ }^{13}$ is irrelevant at the early stage of the infection.

In the present experiments, the fate of virulent bacteria within resistant and susceptible hosts appeared almost identical in two strains of each type of host. The circulating bacterial population (figs. 1A and 2A) and the hepatic bacterial population (figs. $1 \mathrm{~B}$ and $2 \mathrm{~B}$ ) went into rapid growth from day 2 to day 5 , except in the resistant mice inoculated with $2 \times 10^{3}$ 
bacteria in which both the hepatic and the circulating populations failed to increase significantly. The similarity between the changes in bacterial population in the blood and in the liver suggests that the peripheral bacteria may represent predominantly the release of the propagating organisms from the organs and, probably, the peritoneal cavity into the circulation, rather than bacterial multiplication in the blood, as in septicaemia, except perhaps at the terminal phase of a fatal disease. The bacterial growth rate appeared faster in the susceptible host than in the resistant host (figs. $1 \mathrm{~B}$ and 2B). This is consistent with observations by other investigators. ${ }^{1,7.8}$ As the pathogen attained a level of $10^{8}$ bacteria/g of liver, the mice began to die. Thus, susceptible mice died sooner than the resistant ones because their bacterial population reached its peak sooner: it appears that the susceptible host provides a better milieu for bacterial proliferation than its resistant counterpart.

The data here show that there was no difference in the ability of the two types of host to localise the pathogen at the site of entry in the i.p. infection. The organisms rapidly entered the circulation for systemic dissemination (figs. $1 \mathrm{~A}$ and $2 \mathrm{~A}$ ); but once they reached an organ of the RES, they were less able to establish themselves and replicate in the resistant host (figs. 1 B and $2 \mathrm{~B}$ ), which appeared better able to contain the pathogen, rendering it less invasive. Thus, the resistant $\mathrm{A} / \mathrm{J}$ and $\mathrm{CBA}$ mice were able to withstand an i.p. inoculum of $2 \times 10^{3}$ virulent bacteria, whereas the susceptible $\mathrm{C} 57 \mathrm{BL} / 6 \mathrm{~J}$ and $\mathrm{BALB} / \mathrm{c}$ mice rapidly succumbed to a dose of $1 \times 10^{2}$ bacteria. However, there is clearly a threshold of tolerance beyond which the resistant host can no longer suppress the initial challenge. Hence, an i.p. inoculum of $5 \times 10^{4}$ and $6 \times 10^{4}$ bacteria into the $\mathrm{A} / \mathrm{J}$ and CBA mice, respectively, led to an invariably fatal disease. Therefore, the degree of native resistance in the host was relative.

\section{References}

1. Plant J, Glynn AA. Genetics of resistance to infection with Salmonella typhimurium in mice. $J$ Infect Dis $1976 ; 133$ : $72-78$.

2. Lissner CR, Swanson RN, O'Brien AD. Genetic control of the innate resistance of mice to Salmonella typhimurium expression of the Ity gene in peritoneal and splenic macrophages isolated in vitro. J Immunol 1983; 131: 3006-3013.

3. Lissner CR, Weinstein DL, O'Brien AD. Mouse chromosome 1 Ity locus regulates microbicidal activity of isolated peritoneal macrophages against a diverse group of intracellular and extracellular bacteria. $J$ Immunol $1985 ; 135$ : 544-547.

4. Hsu HS. Pathogenesis and immunity in murine salmonellosis. Microbiol Rev 1989; 53: 390-409.

5. Hsu HS, Radcliffe AS. Interactions between macrophages of guinea pigs and salmonellae. I. Fate of Salmonella typhimurium within macrophages of normal guinea pigs. $J$ Bacteriol 1968; 96: 191-197.

6. Plant J, Glynn AA. Locating salmonella resistance gene on mouse chromosome 1. Clin Exp Immunol 1979; 37: 1-6.
We made no attempt to differentiate between the relative abilities of the resistant and susceptible hosts to kill and to permit growth of the pathogen, as others reported. ${ }^{2.9,14,15} \mathrm{~A}$ review has been presented ${ }^{4}$ of the possible genetic control of host macrophages on salmonellae, either by inference from in-vivo experiments or by cell-culture studies. While some investigators speculated on the concept of subsets of macrophages as the safe site for bacterial proliferation, the relevance of macrophages as effector cells, especially in the early stage of murine salmonellosis, remains contrary to histopathological evidence. ${ }^{4,10-12}$ Indeed, the present observations reveal that the ability or inability of the host to contain the systemic bacterial multiplication was shown within the first 4-5 days after inoculation, when macrophages are absent. Moreover, there is now ample in-vivo evidence ${ }^{4,16-19}$ of the destruction of virulent $S$. typhimurium within inflammatory phagocytes, both polymorphs and macrophages, and of its multiplication in the extracellular space of sinusoids and lesions and within hepatocytes. The genetic control on host resistance may well reside in tissue reactions and the early acquired immune response to infection. If the host tissues are viewed as the milieu of bacterial propagation, its net growth rate will be determined by a dynamic balance of the relative ability of the host tissues to interact with the invading bacteria against that of the pathogen to survive and reproduce therein. The contributing factors to this balance are clearly not limited to the macrophage alone. Hence, the genetic basis of host resistance to murine salmonellosis needs to be radically reassessed. Our comparative study on the bacterial dissemination and proliferation in host tissues provides the first step toward that goal.

This study was supported by US Public Health Service grant AI 19434 from the National Institute of Allergy and Infectious Diseases. H.R.X. was a visiting scientist from the Department of Microbiology, Suzhou Medical College, People's Republic of China.

7. Hormaeche CE. Natural resistance to Salmonella typhimurium in different inbred mouse strains. Immunology 1979; 37: 311-318.

8. O'Brien AD, Taylor BA, Rosenstreich DL. Genetic control of natural resistance to Salmonella typhimurium in mice during the late phase of infection. $J$ Immunol 1984; 133 : 3313-3318.

9. Benjamin WH, Hall P, Roberts SJ, Briles DE. The primary effect of the Ity locus is on the rate of growth of Salmonella typhimurium that are relatively protected from killing. $J$ Immunol 1990 ; 144 : 3143-3151.

10. Nakoneczna I, Hsu HS. The comparative histopathology of primary and secondary lesions in murine salmonellosis. $\mathrm{Br}$ $J$ Exp Pathol 1980; 61: 76-84.

11. Nakoneczna I, Hsu HS. Histopathological study of protective immunity against murine salmonellosis induced by killed vaccine. Infect Immun 1983; 39: 423-430.

12. Ding HF, Nakoneczna I, Hsu HS. Protective immunity induced in mice by detoxified salmonella lipopolysaccharide. $J \mathrm{Med}$ Microbiol 1990; 31 : 95-102.

13. Hormaeche CE. Dead salmonellae or their endotoxin accelerate the early course of a Salmonella infection in mice. Microb Pathogen 1990; 9: 213-218. 
14. Hormaeche CE. The in-vivo division and death rates of Salmonella typhimurium in the spleens of naturally resistant and susceptible mice measured by the superinfecting phage technique of Meynell. Immunology 1980; 41: 973-979.

15. Swanson RN, O'Brien AD. Genetic control of the innate resistance of mice to Salmonella typhimurium: Ity gene is expressed in vivo by 24 hours after infection. J Immunol $1983 ; 131$ : 3014-3020

16. Lin FR, Wang XM, Hsu HS, Mumaw VR, Nakoneczna I. Electron microscopic studies on the location of bacterial proliferation in the liver in murine salmonellosis. $B r J$ Exp Pathol 1987; 68: 539-550.
17. Wang XM, Lin FR, Hsu HS, Mumaw VR, Nakoneczna I. Electronmicroscopic studies on the location of salmonella proliferation in the murine spleen. J Med Microbiol 1988; 25: 41-47.

18. Lin FR, Hsu HS, Mumaw VR, Nakoneczna I. Intracellular destruction of salmonellae in genetically resistant mice. $J$ Med Microbiol 1989; 30: 79-87.

19. Lin FR, Hsu HS, Mumaw VR, Moncure CW. Confirmation of destruction of salmonellae within murine peritoneal exudate cells by immunocytochemical technique. Immuno$\log y 1989 ; 67: 394-400$ 